\title{
A cluster of cases of infections due to Aeromonas hydrophila revealed by combined RAPD and ERIC-PCR
}

\author{
A. DAVIN-REGLI, C. BOLLET, E. CHAMOREY*, V. COLONNA D'ISTRIA and ANDREE CREMIEUX \\ EA 2197, Faculté de Pharmacie, 27 Bd Jean Moulin, 13385 Marseille Cedex 5 and * Comité de Lutte contre \\ les Infections Nosocomiales, Hôpital Salvator, 13009 Marseille Cedex 5, France
}

\begin{abstract}
Two polymerase chain reaction (PCR)-based methods were used for epidemiological typing of Aeromonas hydrophila. Random amplification of polymorphic DNA (RAPD) and enterobacterial repetitive intergenic consensus-PCR (ERIC-PCR) were applied to an outbreak involving seven patients. The epidemiological situation appeared complex; with the exception of two clinical isolates, all gave unique patterns with both techniques. These methods demonstrated nosocomial transmission in one unit and permitted the study to exclude a common environmental source in the hospital. The coincidental clustering of patients infected with $A$. hydrophila probably resulted from an increased prevalence of aeromonads in waters during summer, although no single RAPD or ERICPCR pattern was found among both clinical and environmental samples. RAPD and ERIC-PCR proved to be effective for the epidemiological study of $A$. hydrophila strains.
\end{abstract}

\section{Introduction}

Aeromonas species are gram-negative bacteria that can be isolated from water, soil and foodstuffs. Several species are responsible for severe haemorrhagic syndrome in a variety of fishes and multiple diseases in poikilothermic animals [1]. In man, all motile species are potentially pathogenic; half the aeromonads isolated from clinical specimens or hospital environment are A. hydrophila [2]. These motile species have been associated with several categories of human infections, including gastrointestinal infections and extra-intestinal infections, such as endocarditis, meningitis, septicaemia and urinary tract and wound infections. Abscesses or wound infections associated with exposure to soil or water represent the most prevalent extra-intestinal infections $[3,4]$.

In most cases, the origin of the infection is suspected to be environmental, but the causative strain is only rarely isolated, despite intensive screening and the utilisation of highly discriminatory typing methods. Phenotypic methods used to characterise Aeromonas spp. include biotyping, serotyping, esterase electrophoresis, radiolabelled cell proteins and outer-membrane protein profiles [5-9]. Genotypic typing

Received 22 May 1997; revised version accepted 14 Oct. 1997.

Corresponding author: Dr A. Davin-Regli. methods have been applied to these species; plasmid analysis is unhelpful because plasmid carriage is infrequent (20-58\%) in A. hydrophila [4]. In contrast, rRNA gene restriction patterns provide good discrimination within $A$. hydrophila $[10,11]$. However, all the above techniques are time-consuming, expensive and labour intensive and are not able to provide reliable and rapid results on a routine basis. Rapid, simple and cheap methods are desirable for hospital-based laboratories and such PCR-based techniques have been applied successfully to the epidemiological typing of various bacterial species. Random amplification of polymorphic DNA (RAPD) is based on the amplification of random DNA segments with a single primer of arbitrary nucleotide sequence [12]. RAPD has been used widely for epidemiological investigation of numerous bacterial species [13]. Because of the low stringency inherent in this procedure, the patterns generated by RAPD may be affected by experimental parameters and standardisation is crucial. Previous investigations on the reproducibility of RAPD allowed the standardisation of parameters for routine use [14, 15]. An alternative approach based on families of short and repetitive sequences, such as enterobacterial repetitive intergenic consensus (ERIC) sequences, has been used by Versalovic et al. in a genomic fingerprinting method called ERIC-PCR [16]. ERIC sequences represent an extragenic, highly conserved and dispersed DNA sequence that has been observed in many bacterial species. Consensus primers com- 
plementary to each end of the repeated sequence are orientated such that PCR amplification of DNA sequences proceeds between adjacent repeated ERIC elements.

During a 2-month period, five cases of wound infections and two cases of bacteraemia due to $A$. hydrophila were observed in seven patients hospitalised in different units within the same hospital. This unusually high incidence prompted further investigations. Aeromonas spp. isolated from water sources in the hospital were characterised and compared with those from the infections to determine whether there was an association. All clinical strains and aeromonads isolated from water samples from different parts of the hospital distribution system were studied by RAPD and ERIC-PCR. Utilisation of a combination of molecular typing methods is important in order to increase the potential of discrimination by detecting a higher number of polymorphisms, and hence increases confidence in the results. RAPD analysis has been applied previously to the typing of $A$. salmonicida subsp. salmonicida and a few strains of $A$. hydrophila [17]. To our knowledge this is the first application of RAPD and ERIC-PCR in combination to epidemiological typing of $A$. hydrophila.

\section{Materials and methods}

\section{Clinical and environmental isolates}

Between 18 July and 30 Sept. 1995, 10 A. hydrophila isolates were obtained from seven patients hospitalised in five different units of the University Hospital in Marseille, France (Table 1). Patients 1 and 2 were hospitalised in the same ward for 32 days. Patients 1 and 3 received courses of hyperbaric oxygen in the same hyperbaric centre at the same time. Of the 10 isolates of $A$. hydrophila, eight were from wounds or post-operative scars in five patients, and two were responsible for bacteraemia in two patients. Of the seven infections, five were considered nosocomial, as clinical cultures were positive at least $48 \mathrm{~h}$ after hospitalisation. Swab specimens from wound abscesses were obtained with Culturette swabs (Becton Dickinson and Co., Paramus, NJ, USA). Colonies were isolated on blood agar (bioMérieux, Marcy l'Etoile, France) incubated in air at $37^{\circ} \mathrm{C}$ for $24 \mathrm{~h}$. Blood cultures were performed in Bactec 6A culture medium (Becton Dickinson).

Environmental isolates were collected from tap water during epidemiological screening carried out in the different units of the hospital. Thirteen $A$. hydrophila isolates were obtained from the water supply system at four different times (15 May, 26 June, 26 July and 5 Sept. 1995) from four different units (Dermatology, Vascular surgery, Neurosurgery and Haematology) during the study period (Table 1). Water samples $(100 \mathrm{ml})$ were collected and filtered through a 0.45 -

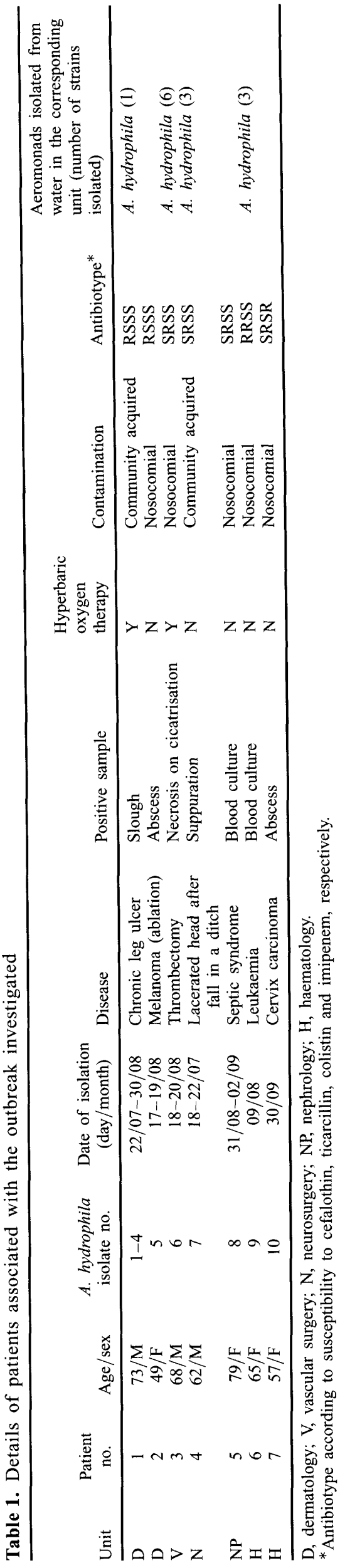


$\mu \mathrm{m}$ membrane that was then placed on Trypticasesoya Agar (bioMérieux). All isolates were identified as below and stored in conservation vials (AES, Combourg, France) at $-80^{\circ} \mathrm{C}$ before epidemiological analysis.

Two isolates of $A$. hydrophila from rectal swabs from patients during the same period, and four strains of $A$. hydrophila from our culture collection were included as controls for comparison.

Finally, epidemiological information concerning $A$. hydrophila isolated from clinical specimens during the last 4 years was obtained for comparison.

\section{Identification}

Clinical and environmental isolates were identified to the species level according to oxidase reaction, growth at $42^{\circ} \mathrm{C}$, and biochemical characteristics by the API 20 $\mathrm{E}$ identification system (bioMérieux), used according to the manufacturer's instructions. Identifications were completed by biochemical reactions according to the schema of Janda [18] together with aesculin hydrolysis and $\beta$-haemolysis.

\section{Susceptibility testing}

Susceptibility to 43 antimicrobial agents and six combinations of agents was determined by a standard disk diffusion method on Mueller-Hinton Agar (bioMérieux) [19].

\section{Epidemiological typing}

The isolates were characterised by RAPD and ERICPCR. For RAPD, the primers were AP12H (5'CGGCCCCTGT-3') and HLW74 (5'-ACGTATCTGC$\left.3^{\prime}\right)[14,15]$. For ERIC-PCR, the primers were ERIC1R (5'-ATGTAAGCTCCTGGGGATTCAC-3') and ERIC2 (5'-AAGTAAGTGACTGGGGTGAGCG-3') [16]. For DNA preparation, isolates were grown overnight at $37^{\circ} \mathrm{C}$ on Mueller-Hinton agar. Total cellular DNA was extracted by the Chelex technique [20]. Five bacterial colonies were washed in a $1.5-\mathrm{ml}$ eppendorf tube containing $1 \mathrm{ml}$ of TE buffer $(10 \mathrm{mM}$ Tris, $\mathrm{pH} 8.0$, $10 \mathrm{~mm}$ EDTA) by centrifugation for $5 \mathrm{~min}$ at $14000 \mathrm{~g}$. The bacterial pellet was resuspended in $100 \mu \mathrm{l}$ of TE buffer and $150 \mu \mathrm{l}$ of lysis solution (Chelex 100 (BioRad) $15 \%$, SDS $1 \%$, Nonidet P40 1\% and Tween $201 \%$ were added. After mixing, the sample was incubated at $90^{\circ} \mathrm{C}$ for $30 \mathrm{~min}$, centrifuged for $10 \mathrm{~min}$ at $14000 \mathrm{~g}$ and the supernate was transferred to a new tube. DNA concentrations were estimated by comparison with standards on agarose gels. Amplification reactions were performed in a total volume of $47 \mu \mathrm{l}$ containing $100 \mu \mathrm{M} \quad \mathrm{dATP}, 100 \mu \mathrm{M} \quad \mathrm{dCTP}, 100 \mu \mathrm{M}$ dGTP and $100 \mu \mathrm{M}$ dTTP, plus $0.2 \mu \mathrm{M}$ primer, $25 \mathrm{ng}$ of template DNA and 1.25 units of Taq polymerase (Perkin-Elmer/Cetus, Norwalk, CT, USA) in $1 \times$ PCR buffer $(20 \mathrm{mM}$ Tris- $\mathrm{HCl}, \mathrm{pH} 8.3,50 \mathrm{mM} \mathrm{KCl}, 3 \mathrm{mM}$ $\mathrm{MgCl}_{2}$, gelatin $0.001 \% \mathrm{w} / \mathrm{v}$ ). A negative control without template DNA was included in each experiment. The reaction mixtures were overlaid with mineral oil and subjected to amplification in a DNA thermal cycler (TR2, Cera-Labo, Aubervilliers, France) programmed for 45 cycles of $1 \mathrm{~min}$ at $94^{\circ} \mathrm{C}$, $1 \mathrm{~min}$ at $45^{\circ} \mathrm{C}$ and $1 \mathrm{~min}$ at $74^{\circ} \mathrm{C}$. Amplification products $(10 \mu \mathrm{l}$ samples) were electrophoresed in agarose $1.2 \%$ gels in Tris-acetate buffer $(0.04 \mathrm{M}$ Tris-acetate, $0.001 \mathrm{M}$ EDTA, $\mathrm{pH} 8.2$ ), and then stained with ethidium bromide and photographed on a UV light transilluminator. A molecular size standard (Marker V, Boehringer-Mannheim, Germany) was included on each gel. Fingerprint patterns were interpreted and compared without knowledge of epidemiological data. Heterogeneity with respect to the intensity and shape of bands was not considered to be a difference. Strains were considered different if their profiles differed by two or more bands as in previous studies [21].

For each of the PCR-based techniques, reproducibility was determined by testing at least two independent DNA preparations extracted from single-colony cultures at different times, amplified on at least two occasions.

\section{Results}

During the last 6 years, 27 isolates of $A$. hydrophila were obtained from clinical specimens in the laboratory (of which eight were isolated in 1994 and 10 in 1995); in most cases these were associated with wound infections or bacteraemia. Twenty of these 27 isolates (74\%) were isolated during the summer period (JuneSept.).

All 10 clinical isolates from the summer of 1995 were obtained in pure culture except isolates 1,2 and 3 from patient 1 , which were associated with a Proteus mirabilis strain. Four antibiotic susceptibility patterns which varied in susceptibility to cefalothin, ticarcillin, colistin and imipenem were detected amongst the isolates. No variations in antimicrobial resistance patterns were observed between isolates 1-4 from patient 1. All isolates were resistant to penicillin, ampicillin, pristinamycin and erythromycin.

Twenty-six tap water specimens were collected from the five hospital units concerned. In half of them, between 1 and 30000 colonies of $A$. hydrophila were isolated. Representative colonies of $A$. hydrophila isolates from each of the 13 positive water sources were studied.

RAPD and ERIC-PCR with single primers successfully typed all the isolates. Patterns obtained with independent extracts from one isolate and amplified in two 
independent experiments were equivalent except for fainter intensity of bands (data not shown). RAPD and ERIC fingerprints for all strains studied are represented in Figs. 1 and 2. A perfect correlation was found between the two PCR typing methods. The results from the PCR typing methods for each strain are presented in Table 2. Among the 10 clinical isolates, six different PCR-patterns were identified. The four isolates from patient 1 and the isolate from patient 2 had identical RAPD and ERIC fingerprints. All other clinical isolates and strains used as controls gave different patterns. The 13 A. hydrophila isolated from the different water sources gave seven different patterns with each primer; in two cases, four strains belonged to the same RAPD and ERIC type. No fingerprints were common to both environmental and clinical isolates.

\section{Discussion}

From 1989 to 1994, 27 cases of A. hydrophila infections were observed in Sainte Marguerite Hospital (Marseille, France), i.e., about four cases each year. During a 3-month period in 1995, seven patients from different units were infected by $A$. hydrophila, corresponding to a notable increase in the prevalence of this species.

Two molecular typing methods based on PCR, RAPD and ERIC-PCR, were used to compare isolates from water samples with those from patients to answer rapidly the following questions: (1) is the hospital water supply the origin of clinical infections and is there any relationship between patient strains and (2) could patients have been contaminated during common clinical procedures such as dermatological therapy and hyperbaric oxygen therapy?

A great heterogeneity was demonstrated in both clinical and environmental strains of $A$. hydrophila. Typing results revealed that five isolates from two patients were identical. In contrast, other clinical strains and those used as controls showed different patterns. Therefore, analysis of the PCR fingerprinting patterns confirmed that patients 1 and 2 were infected by a single $A$. hydrophila strain. These patients were hospitalised in the same dermatological unit during a common period of 32 days. Moreover, they resided in the same room 15 days apart. The medical files revealed that patient 1 , who was obese and rowdy, had broken his bathtub. He was put in another room so that repairs could be made. Fifteen days after the repairs, patient 2 was hospitalised in the same room and used the same bathtub. Although no Aeromonas strains were found in any sample from the bathtub water, it is possible that patient 2 was infected through the bathtub or water. In previous reports of $A$. hydrophila infection, it is generally thought that the strain causing wound infections is of environmental origin, but identical environmental strains are rarely found. As patients 1 and 3 were treated in the same hyperbaric centre at the same time, this suggested possible transmission during their treatment. However, the typing results excluded this possibility.

\section{a}

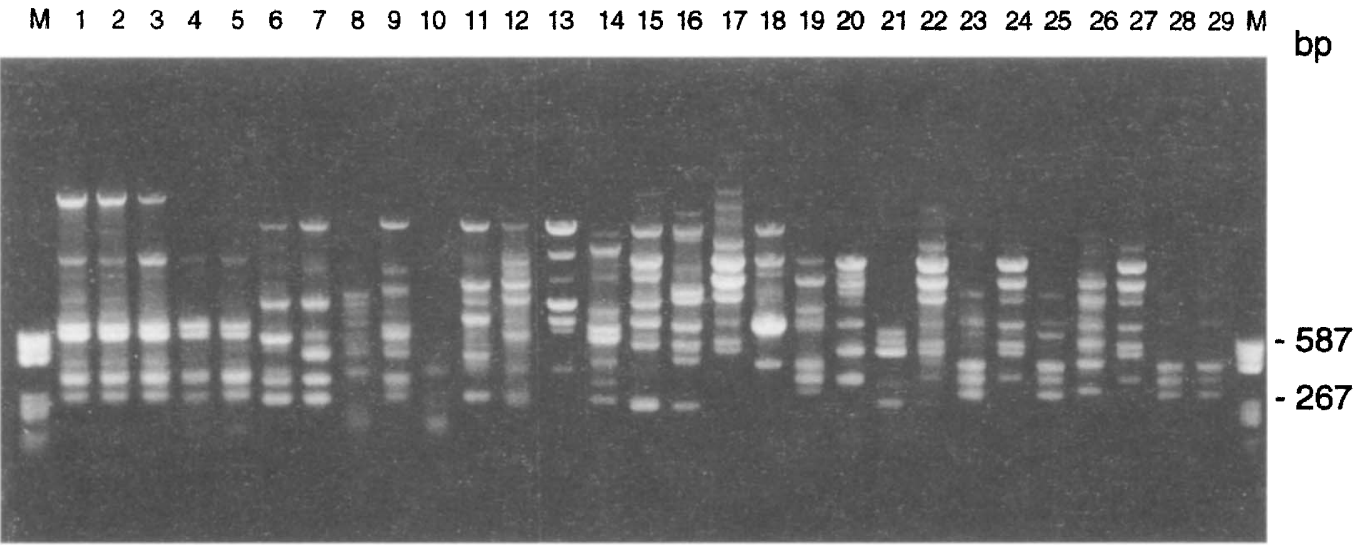

b

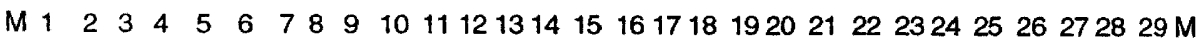

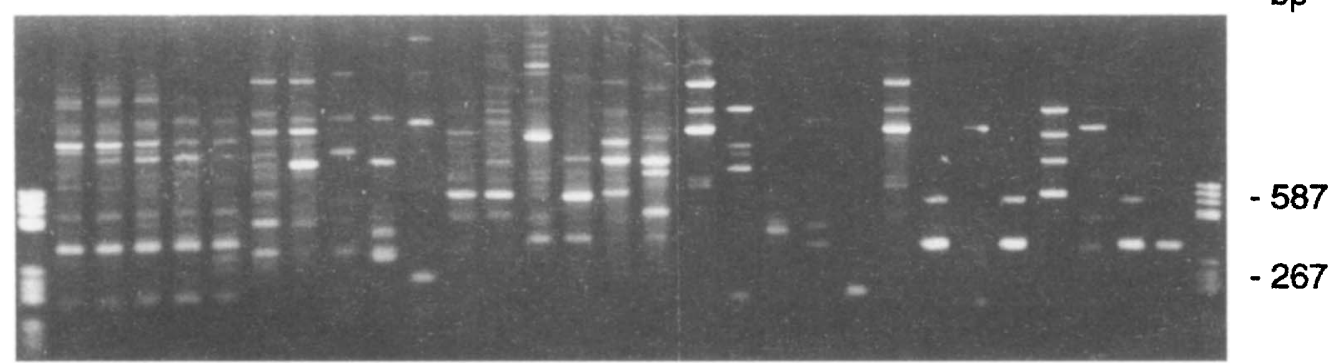

Fig. 1. Representative RAPD fingerprints of clinical and environmental isolates of $A$. hydrophila, obtained with primer AP12H (a) or HLW74 (b). The numbers at the top are the isolate numbers listed in Table 2. Lane M: size marker V. 


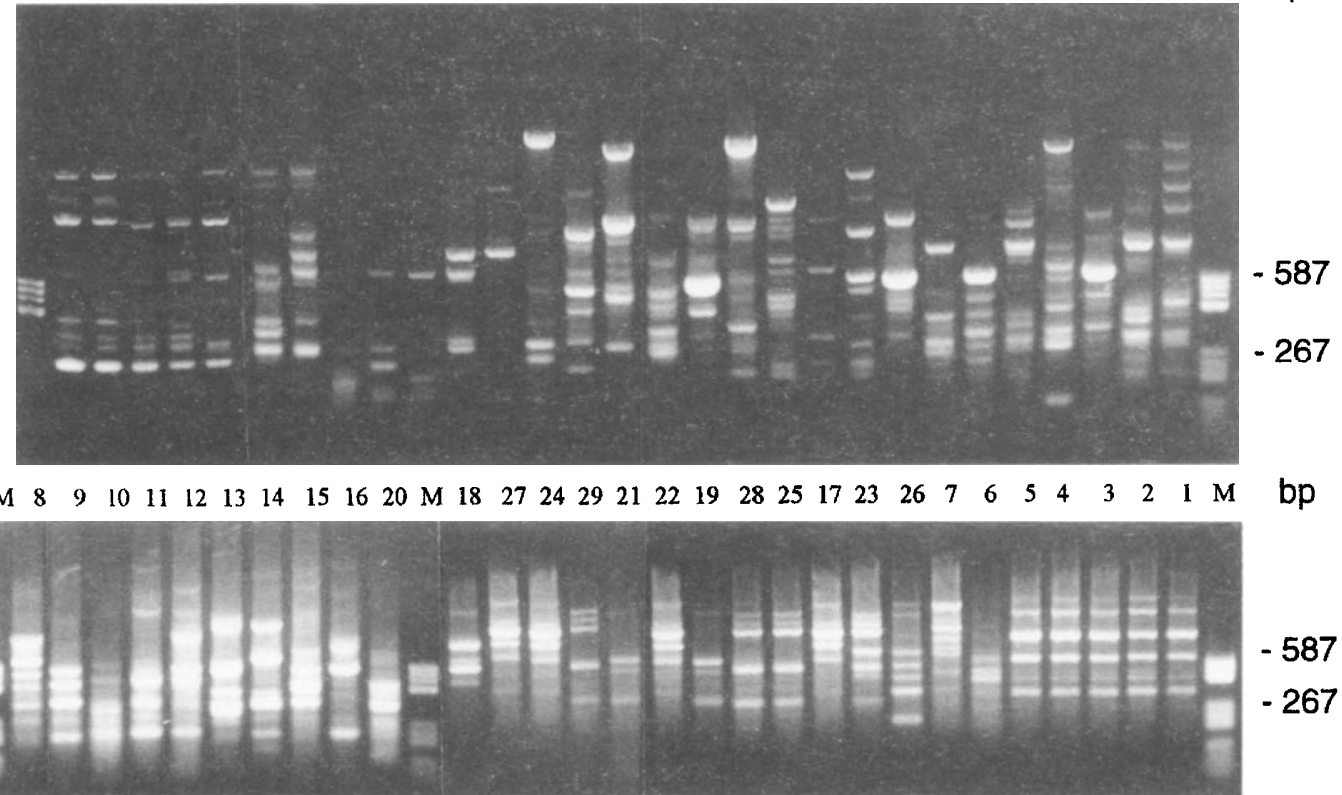

Fig. 2. Representative ERIC-PCR fingerprints of clinical and environmental isolates of $A$. hydrophila, obtained with primer ERIC 1R (a) or ERIC 2 (b). The numbers at the top are the isolate numbers listed in Table 2. Lane M: size marker V.

In two cases, isolates were considered to be community-acquired. Patient 1 was suffering from chronic ulcers of the leg with scabs and was infected on admission by $A$. hydrophila. He was working in naval repairs and was in contact with the marine environment. Patient 4 was found lying in a ditch after a fall. His head was lacerated and immersed in sludge.
Although aeromonas bacteraemia is probably endogenous in origin (from the gastrointestinal tract or infected wounds), there are few reports documenting the source of the original gastrointestinal or wound infection [4]. In the present study, patients 5 and 6 were suffering from diarrhoea, acquired $>48 \mathrm{~h}$ after hospitalisation, before the onset of their nosocomially

Table 2. Origin and genotyping results of $A$. hydrophila isolates studied

\begin{tabular}{|c|c|c|c|c|c|}
\hline \multirow{2}{*}{$\begin{array}{l}\text { A. hydrophila } \\
\text { isolate no. }\end{array}$} & \multirow[b]{2}{*}{ Origin } & \multicolumn{2}{|c|}{ RAPD type with primer } & \multicolumn{2}{|c|}{ ERIC type with primer } \\
\hline & & AP12h & HLW74 & ERIC $1 \mathrm{R}$ & ERIC 2 \\
\hline 1 & Clinical (patient 1) & 1 & 1 & 1 & 1 \\
\hline 2 & Clinical (patient 1) & 1 & 1 & 1 & 1 \\
\hline 3 & Clinical (patient 1) & 1 & 1 & 1 & 1 \\
\hline 4 & Clinical (patient 1) & 1 & 1 & 1 & 1 \\
\hline 5 & Clinical (patient 2) & 1 & 1 & 1 & 1 \\
\hline 6 & Clinical (patient 3) & 2 & 2 & 2 & 2 \\
\hline 7 & Clinical (patient 4) & 3 & 3 & 3 & 3 \\
\hline 8 & Clinical (patient 5) & 4 & 4 & 4 & 4 \\
\hline 9 & Clinical (patient 6) & 5 & 5 & 5 & 5 \\
\hline 10 & Clinical (patient 7) & 6 & 6 & 6 & 6 \\
\hline 11 & Control (rectal swab) & 7 & 7 & 7 & 7 \\
\hline 12 & Control (rectal swab) & 8 & 8 & 8 & 8 \\
\hline 13 & Control (collection) & 9 & 9 & 9 & 9 \\
\hline 14 & Control (collection) & 10 & 10 & 10 & 10 \\
\hline 15 & Control (collection) & 11 & 11 & 11 & 11 \\
\hline 16 & Control (collection) & 12 & 12 & 12 & 12 \\
\hline 17 & Environmental (unit N) & 13 & 13 & 13 & 13 \\
\hline 18 & Environmental (unit N) & 14 & 14 & 14 & 14 \\
\hline 19 & Environmental (unit $\mathrm{N}$ ) & 15 & 15 & 15 & 15 \\
\hline 20 & Environmental (unit $\mathrm{H}$ ) & 16 & 16 & 16 & 16 \\
\hline 21 & Environmental (unit $\mathrm{H}$ ) & 17 & 17 & 17 & 17 \\
\hline 22 & Environmental (unit $\mathrm{H}$ ) & 13 & 13 & 13 & 13 \\
\hline 23 & Environmental (unit V) & 18 & 18 & 18 & 18 \\
\hline 24 & Environmental (unit V) & 13 & 13 & 13 & 13 \\
\hline 25 & Environmental (unit V) & 18 & 18 & 18 & 18 \\
\hline 26 & Environmental (unit V) & 19 & 19 & 19 & 19 \\
\hline 27 & Environmental (unit V) & 13 & 13 & 13 & 13 \\
\hline 28 & Environmental (unit V) & 18 & 18 & 18 & 18 \\
\hline 29 & Environmental (unit D) & 18 & 18 & 18 & 18 \\
\hline
\end{tabular}

$\mathrm{D}$, dermatology; V, vascular surgery; $\mathrm{N}$, neurosurgery; NP, nephrology; $\mathrm{H}$, haematology. 
acquired bacteraemia. No faecal carriage was investigated during the diarrhoeal episodes, but a relationship between $A$. hydrophila enteric carriage and the septicaemias cannot be excluded. In a review of the literature Altwegg et al. noted that $A$. hydrophila invades the bloodstream from the gastrointestinal tract through a defective intestinal mucosa although only a few stool cultures are found to be positive for Aeromonas strains at the same time [1].

The present study revealed the co-existence of multiple $A$. hydrophila strains in water samples collected in the same unit and the existence of a single strain isolated over a period of 4 months from water samples from different units. The finding of common types (type 13 and type 18) of A. hydrophila in three separate hospital units suggested that they were present in the water distribution system. Kuhn et al. [6] have shown that a single strain could be found in several sampling sites and at different times in the public drinking water distribution system. The results of the present study demonstrate colonisation of public water supplies with some widespread clones of $A$. hydrophila. The high number of $A$. hydrophila environmental strains collected correlated with the increase in clinical cases, as observed elsewhere [8, 10]. However, no relationship between clinical and environmental aeromonads could be demonstrated by RAPD or ERIC-PCR. Colonisation or infection of hospitalised patients by Aeromonas species from hospital water supplies has been suggested $[2,8,22$, 23], but environmental sources are rarely detected. It seems probable that an association of hot weather and increased water usage (drinks, baths and showers etc.) may have led to the increase in $A$. hydrophila infections. Moreover, the clinical isolates of $A$. hydrophila were all obtained during June-Oct. and the abundance of $A$. hydrophila in fresh water has been found to be seasonally distributed, with a maximum occuring during the summer [23, 24]. In this study, strains from patients and environmental sources were different, but it seems likely that water sources other than those investigated were involved in contaminating patients.

The typing methods, RAPD and ERIC-PCR, showed that the apparently large outbreak was due to the superposition of a horizontal transmission, involving only two patients, and a series of sporadic cases, probably due to an increase in the contamination of the water supply by $A$. hydrophila.

\section{References}

1. Altwegg M, Geiss HK. Aeromonas as a human pathogen. Crit Rev Microbiol 1989; 16: 253-286.

2. Chattopadhyay B. Aeromonas in hospital. J Hosp Infect 1986; 7: $103-107$
3. Isaacs RD, Paviour SD, Bunker DE, Lang SDR. Wound infection with aerogenic Aeromonas strains: a review of twenty-seven cases. Eur J Clin Microbiol Infect Dis 1988; 7: $355-360$.

4. Janda JM. Recent advances in the study of the taxonomy, pathogenicity, and infectious syndromes associated with the genus Aeromonas. Clin Microbiol Rev 1991; 4: 397-410.

5. Carnahan A, Hammontree L, Bourgeois L, Joseph SW. Pyrazinamidase activity as a phenotypic marker for several Aeromonas spp. isolated from clinical specimens. $J$ Clin Microbiol 1990; 28: 391-392.

6. Kühn I, Lindberg T, Olsson K, Strenström T. Biochemical fingerprinting for typing of Aeromonas strains from food and water. Letts Appl Microbiol 1992; 15: 261-265.

7. Kuijper EJ, Steigerwalt AG, Schoenmakers BSCIM, Peeters MF, Zanen HC, Brenner DJ. Phenotypic characterization and DNA relatedness in human fecal isolates of Aeromonas spp. $J$ Clin Microbiol 1989; 27: 132-138.

8. Picard B, Goullet $\mathrm{Ph}$. Epidemiological complexity of hospital aeromonas infections revealed by electrophoretic typing esterases. Epidemiol Infect 1987; 98: 5-14.

9. Stephenson JR, Millership SE, Tabaqchali S. Typing of Aeromonas species by polyacrylamide-gel electrophoresis of radiolabelled cell proteins. $J$ Med Microbiol 1987; 24: 113-118.

10. Kuijper EJ, van Alphen L, Leenders E, Zanen HC. Typing of Aeromonas strains by DNA restriction endonuclease analysis and polyacrylamide gel electrophoresis of cell envelopes. $J$ Clin Microbiol 1989; 27: 1280-1285.

11. Moyer NP, Martinetti G, Lüthy-Hottenstein J, Altwegg M. Value of rRNA gene restriction patterns of Aeromonas spp. for epidemiological investigations. Curr Microbiol 1992; 24: 15-21.

12. Williams JGK, Kubelik AR, Livak KJ, Rafalski JA, Tingey SV. DNA polymorphisms amplified by arbitrary primers are useful as genetic markers. Nucleic Acids Res 1990; 18: 6531-6535.

13. van Belkum A. DNA fingerprinting of medically important microorganisms by use of PCR. Clin Microbiol Rev 1994; 7: $174-184$.

14. Abed Y, Davin A, Charrel RN, Bollet C, De Micco P. Variation of RAPD-fingerprint patterns using different DNA-extraction methods with Gram-positive bacteria. World $J$ Microbiol Biotechnol 1995; 11: 238-239.

15. Davin-Regli A, Abed Y, Charrel RN, Bollet C, de Micco P The variation in DNA concentrations significantly affect the reproducibility of RAPD fingerprint patterns. Res Microbiol 1995; 146: $561-568$.

16. Versalovic J, Koeuth T, Lupski JR. Distribution of repetitive DNA sequences in eubacteria and application to fingerprinting of bacterial genomes. Nucleic Acids Res 1991; 19: 6823-6831.

17. Miyata M, Aoki T, Inglis V, Yoshida T, Endo M. RAPD analysis of Aeromonas salmonicida and Aeromonas hydrophila. $J$ Appl Bacteriol 1995; 79: 181-185.

18. Janda JM, Reitano M, Bottone EJ. Biotyping of Aeromonas isolates as a correlate to delineating a species-associated disease spectrum. $J$ Clin Microbiol 1984; 19: 44-47.

19. National Committee for Clinical Laboratory Standards. Performance standards for antimicrobial disk susceptibility tests. Publication no. M2A2. Villanova, PA, National Committee for Clinical Laboratory Standards. 1992.

20. de Lamballerie X, Zandotti C, Vignoli C, Bollet C, de Micco P A one-step microbial DNA extraction method using "Chelex 100" suitable for gene amplification. Res Microbiol 1992; 143: 785-790.

21. Woods CR, Versalovic J, Koeuth T, Lupski JR. Analysis of relationships among isolates of Citrobacter diversus by using DNA fingerprints generated by repetitive sequence-based primers in the polymerase chain reaction. J Clin Microbiol 1992; 30: $2921-2929$

22. Mellersh AR, Norman P, Smith GH. Aeromonas hydrophila: an outbreak of hospital infection. J Hosp Infect 1984; 5: 425-430.

23. Millership SE, Chattopadhyay B. Aeromonas hydrophila in chlorinated water supplies. J Hosp Infect 1985; 6: 75-80.

24. Monfort P, Baleux B. Dynamics of Aeromonas hydrophila Aeromonas sobria, and Aeromonas caviae in a sewage treatment pond. Appl Environ Microbiol 1990; 56: 1999-2006. 